\title{
A Decentralized and Sustainable Solution to the Problems of Dumping Menstrual Waste into Landfills and Related Health Hazards in India
}

\author{
Gautami Bhor ${ }^{1}$, Sayali Ponkshe ${ }^{2}$
}

\begin{abstract}
In a nation like India which consists of 655 million women, $48 \%$ of them are not aware of the proper usage of a sanitary napkin. Disposal of used sanitary pads is a major challenge across India. This study investigates how women manage menstrual waste and the amount of sanitary waste that ends up into landfill. Lack of awareness and immense taboo around menstruation in India adds up to the issues of proper sanitary waste management. This infectious waste, if not handled properly, would pose an immense threat to the oceans, land, and human health. So far while importance was given only to promoting the usage of sanitary napkins, it is equally important that the problems caused by dumping sanitary waste in landfills be addressed. Considering the various hazards caused by this widely accepted yet problematic disposal method, it is necessary to come up with a solution that is sustainable on every front. To avoid proliferation of the problem, a decentralized solution to handle the menstrual waste at its generation point is vital. With this study, we try to conclude best practices to be observed and put forth a solution that is more economical, viable and rational than landfill dumping.
\end{abstract}

Keywords: Menstrual waste, Landfills, Land and water pollution, Health of waste pickers, Decentralized solution

\section{Introduction}

India is a country of 1.3 billion people living in different regions and under different circumstances; some live a lavish lifestyle while some struggle for food. However, one thing is common for every individual all over the country is their generation of waste, which greatly makes solid waste management a crucial issue in India. Increasing industrialization and urbanization is worsening the situation every day. There are different types of wastes like food waste, commercial waste, garden waste, electronic waste, medical and sanitary waste, demolition waste; and every country has different approach towards handling this waste. It is necessary that every waste should be handled and disposed separately. The quantity of Municipal Solid Waste (MSW) generated in different countries depends upon a number of factors such as food habits, standard of living, degree of commercialization and seasons. (Sharholy, 2007)

The MSW has to be handled in 3 stages: collection, transportation and disposal. The management of MSW is going through a critical phase, due to unavailability of suitable facilities to treat and dispose off the large amount of MSW generated daily in metropolitan cities.(Sharholy, 2007) If not handled properly, this waste can be harmful for the environment as well as human health. One such type of waste is the sanitary 
waste. Sanitary waste or menstrual waste disposal is a crucial issue in today's scenario; not only in India, but all over the world. Handling this waste is a problem on many fronts. Owing to the disposal management techniques and superstition around menstruation, it is necessary to come up with a solution that will manage sanitary waste on all fronts.

\section{Current Scenario of Menstruation in India}

\subsection{Types of Products Used}

Around 48\% Indian women still use cloth during their periods. Sanitary napkins are gradually being accepted in the rural areas as well. Products like tampons, biodegradable napkins and menstrual cups are just being introduced. To conclude, sanitary napkin is currently the most widely used product in India. Owing to the immense taboo spread in the country related to menstruation, women are still reluctant to use proper hygienic sanitary products. Long-forgotten traditions are still being followed in some villages which cause problems related to health amongst women. Using ash, soil, dried leaves during periods to soak the blood is even carried on today. It is absolutely essential that women be made aware about the importance of using hygienic sanitation products to avoid infections and other health issues.

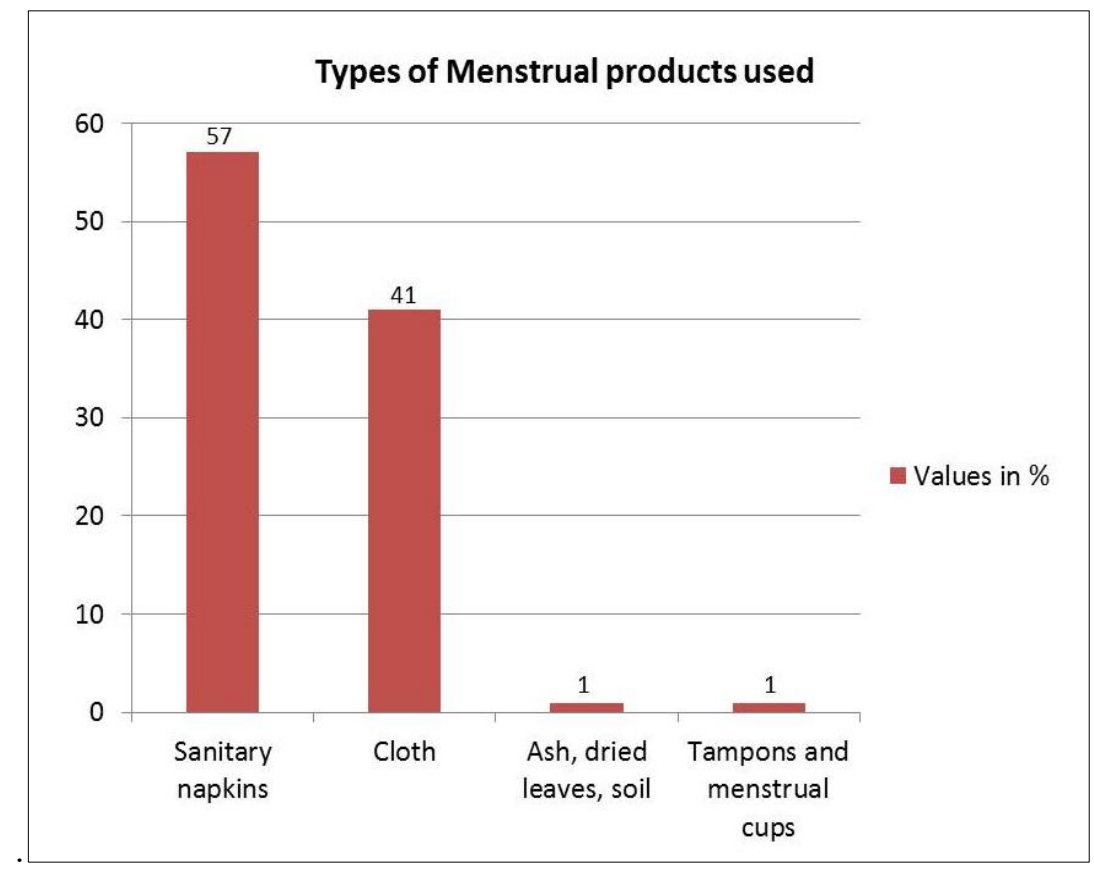

Fig. 1. Types of Menstrual products used in India

\subsection{Cultural Beliefs and Taboo Related to Menstruation}

Menstruation is not considered just a natural process in India, since a lot of its practices are affected by variety of cultural norms, beliefs, parental influence, personal 
preferences, economic status, stories and socio-economic pressures. Despite solid efforts of different organizations and government, taboo around menstruation is still a huge problem, especially in the rural areas. Menstrual beliefs refer to misconceptions and attitudes towards menstruation within any specific cultural group or community. These misconceptions and taboo are the major factors contributing towards an ignorant attitude and lack of platform to discuss about the menstrual problems. (Kaur R. et al, 2018)

Considering menstruation as unclean or embarrassing, many women experience restrictions on cooking, work activities, sexual intercourse, bathing, worshipping, and eating certain foods. Many girls also opted to skip schools due to lack of resources. (Kaur R. et al, 2018)

Profoundly a cloth is used as an absorbent in most of the rural areas where they are washed and reused again. Washing and drying is to be done secretly or in a hidden corner so that it cannot be seen by others. It was believed that menstrual fluids may be misused for black magic, so women should wash the wrapper/cloth wore during menses only at night when others were asleep. The cloths are also usually washed and dried in dark or without the presence of sunlight, which makes the cloths prone to even more bacterial formation.(Sripada, 2014) Menstrual flow is seen as dirty, polluting, and shameful, so women hide menstrual cloths from fear of being cursed. These problems lead to increased infections and medical issues in women. Women keep themselves isolated during these days and keep no contact with people. They are served food in an isolated environment, they are not allowed in religious places, and moreover, they aren't even allowed to talk about their issues to any senior member or male in the family.

\section{Disposal of Menstrual Waste}

\subsection{Amount of Sanitary Waste Generated}

Despite the under usage of proper sanitary products in India, menstrual waste is increasing day-by-day owing to the ever increasing population. An average woman throws away around $150 \mathrm{~kg}$ of non-biodegradable waste every year. (Sahoo, 2016) With changing demographics and preferences, the amount of non-biodegradable sanitary napkins used in India is growing. As women are becoming more aware about the importance of using hygienic sanitary products, the number of sanitary napkins used per month is going to increase rapidly. Different eco-friendly products like biodegradable napkins and menstrual cups have recently started gaining importance; however it will be years before the usage of non-biodegradable sanitary napkins scales down.

If an estimated 121 million women and adolescent girls are currently using an average of 8 disposable napkins every month, the waste load generated in India is estimated to be: -1.021 million pads disposed monthly

-12.3 billion pads disposed annually

$-113,000$ tonnes of menstrual waste generated annually (1"Management of Menstrual Waste")

\subsection{Menstrual Waste Disposal Techniques Used}

Products used during menstruation and its disposal techniques vary from 
whether the woman stays in rural area or urban and even whether there are adequate disposal facilities available for her. Most of the women dispose of their sanitary pads or other menstrual products into garbage bins that ultimately become a part of municipal solid waste. In urban areas, where modern disposable menstrual products are used they dispose of them by flushing in toilets and throwing in dustbins. In rural areas, women use reusable and non-commercial sanitary materials like reusable pads or cloths, thus generating lesser amount of sanitary waste as compared to those using disposal and one time used pads in big cities. Rural areas provide many more options for disposing menstrual waste such as by burying, burning, and throwing in garbage or in pit latrines. The disposal method of a menstrual product largely depends even on the cultural beliefs and location or time of disposal, since menstruation is still considered as something to be kept private and secretive, women prefer to dispose their products or wash them in private and bury or burn only at night or when no person, especially men are around. At some locations, incinerators are used for disposing menstrual waste material but due to shyness or fear of being seen by others they refrained from using it.

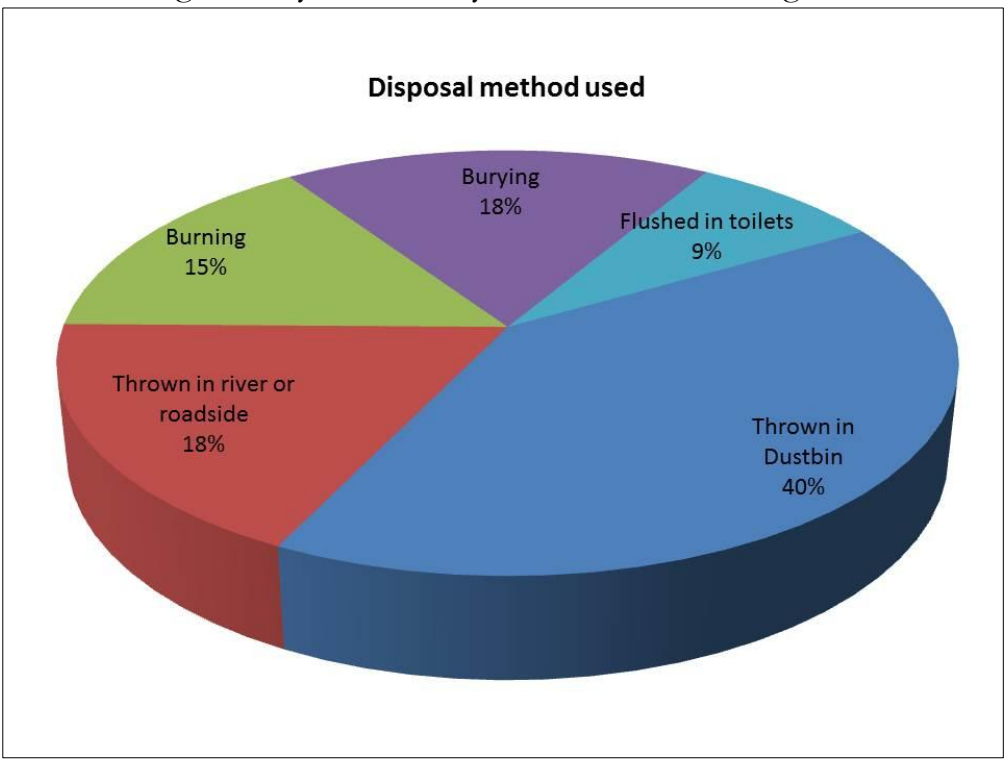

Fig. 2. Different sanitary waste disposal methods followed in India

Toilet facilities in India lack bins for the disposal of sanitary pads and hand washing facilities for menstruating women to handle menstrual hygiene. The situation is even worse when it comes to public toilets either at a rural or urban location. The toilet doors usually have broken lock, lack of water tap, bucket, and poor water supply are some to the common issues observed at a public washroom. Thus, women are forced to flush the pads in the toilets or wrap and throw them in the dustbins. Where dustbins are not placed they leave the soiled pads wrapped or unwrapped in the toilet corners. (Kaur R. et al, 2018) This makes the toilets dirty, breeding place for flies and mosquitoes, and also unhygienic for other toilet users and cleaners. All these above unhygienic practices create a lot of health issues and infection for whoever is exposed to them or have to clean the 
areas.

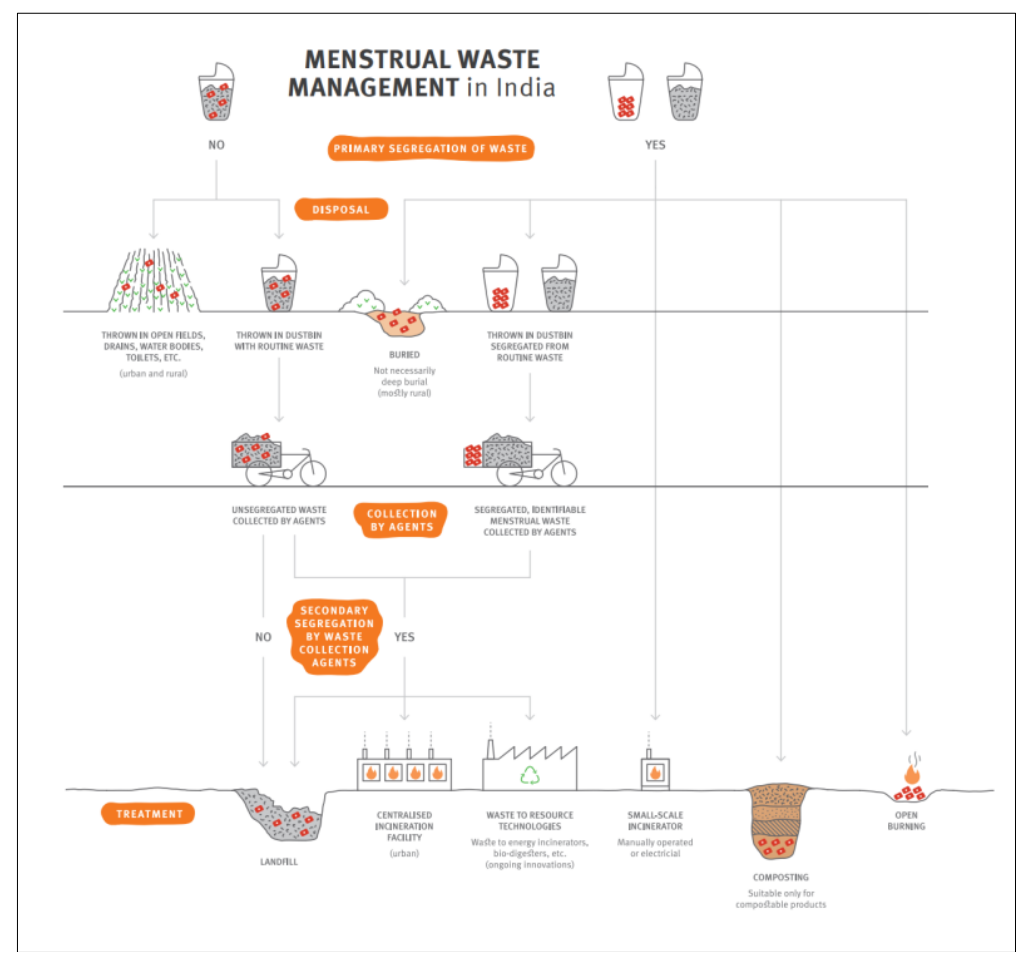

Fig. 3 A depiction of how sanitary waste in handled in different stages. Source: ${ }^{1}$ Management of Menstrual Waste.

\section{Case Study on Waste Pickers}

A case study or survey was conducted on the waste pickers living in the city of Pune, India to understand their daily practices, the amount of waste they collect every day and what challenges they face while doing the same every morning. The survey gave us a broader perspective towards the waste collection and segregation mechanisms observed in our city and how a sanitary pad or any menstrual waste enters into the garbage or municipal solid waste.

A survey on total of 30 waste pickers was collected, where we monitored them since 6 a.m. in the morning for the next 3-4 hours until they had collected the waste from all households and institutions. Following are the observations and conclusions of our survey.

\subsection{Observations}

Manda, a waste picker of $\mathrm{SWaCH}$, (an organization that manages networks of all the waste pickers in the city) starts her day at $5 \mathrm{a} . \mathrm{m}$. in the morning. After completing her daily household tasks she goes out with other SWaCH workers in her community to pick up the cart and bins for waste collection. Her tasks usually involve collecting waste from doorsteps and segregating the waste. Often the waste is given segregated by the citizens but many times she has to go through a hard time picking each and every material from the waste and putting it into dry or wet bins. She covers approximately $250+$ households 
every day.
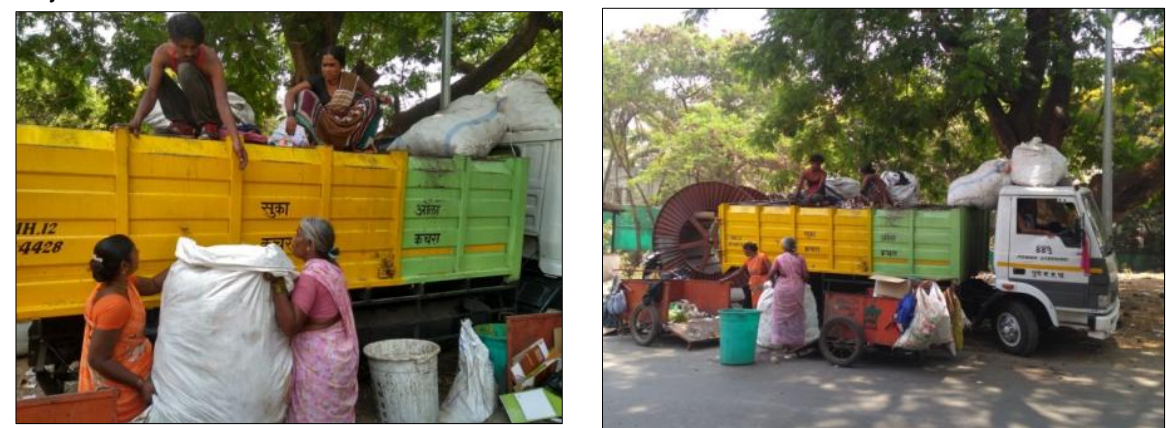

Fig. 4 \& 5 Loading all the waste into a truck.

In the majority parts of India, waste is segregated into only 2 categories i.e.; wet waste and dry waste. There is no separate collection for menstrual waste or diapers. They usually end up into dry waste, which are then taken for either burning or dumped openly into the landfills. Manda and many other waste pickers that were surveyed complained that in spite of recurring instructions given to households to wrap the used sanitary pads with newspaper and put a big red dot onto it so as to easily identify sanitary waste, many women do not abide by the instructions. There were also many incidents where the waste pickers found used menstrual pad thrown directly into the bins and they had to handle them with their bare hands. This not only makes the waste pickers prone to infections and diseases but also exposes them to very filthy and inhuman situations.
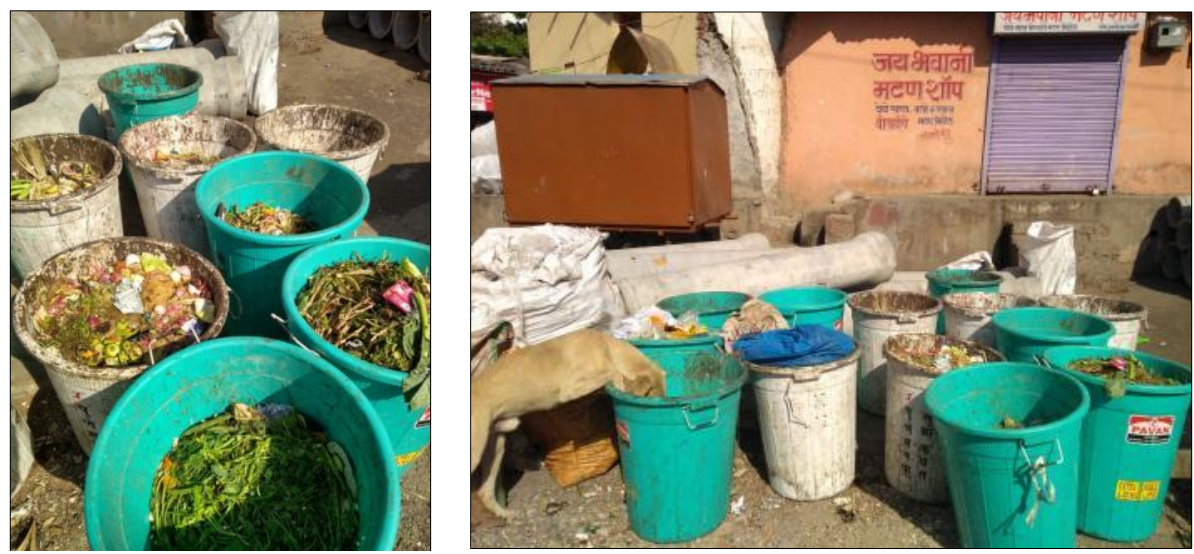

Fig. 6 \& 7 Wet and dry waste, Amount of waste collected by one waste-picker

Considering the magnitude of convenience the waste pickers plays in our lives that contribute towards the local economy, public health and safety, and to environmental sustainability, they get very low social status, deplorable working conditions and little support from the local government bodies. (3"Waste Pickers") They receive remuneration of as low as Rs.35 per month from one household. A lack of attention and support was observed with just one basic health check-up in a year, lack of gloves and masks availability was also prominent. 


\subsection{Conclusion}

Waste collection and segregation is the most crucial part for any waste management system and to ensure that proper menstrual waste is managed ethically, a solution that is convenient and capable to taking the pain away from these waste pickers becomes vital.

\section{Potential Environmental Impact}

Over a billion non-compostable sanitary pads are making their way into sewerage systems, landfills, fields and water bodies in India every month, posing huge environmental and health risks. With taboos and superstitions galore about menstruating women in India, safe technologies and interventions to dispose and treat menstrual waste have become a huge challenge.("How Disposable Sanitary Napkins Affect Environment", 2017) A Life Cycle Assessment of tampons conducted by the Royal Institute of Technology in Stockholm, found that the largest impact on global warming was caused by the processing of LDPE (low-density polyethylene, a thermoplastic made from the monomer ethylene) used in tampon applicators as well as in the plastic backstrip of a sanitary napkin requiring high amounts of fossil fuel generated energy.("2Occupational health of waste pickers in Pune: KKPKP and SWaCH members push for health rights", 2013) A year's worth of a typical feminine hygiene product leaves a carbon footprint of $5.3 \mathrm{~kg}$ CO2 equivalent.(Shreya, 2016)

An average woman will use around 16,000 or more tampons or pads in her lifetime. That's 7 billion tampons and pads landing in landfills each year. Most of them contain chemicals, toxins, additives and synthetic materials such as plastic. The plastics, first of all, take a very long time to breakdown. Second, they also end up leaking into nature, and polluting our rivers, lakes, streams and world.(Syren, 2016) In 2010, a UK beach clean found an average of 23 sanitary pads and 9 tampon applicators per kilometre of British coastline. Non-organic sanitary products are made from cotton that was sprayed with chemical pesticides, which destroy biodiversity and cause potentially lethal pesticide poisoning in cotton workers. ("Seeing RED: Sanitary Protection and The Environment")

\section{Potential Health Impact on Women and Waste-pickers}

The case-study provided above delivers detailed insights into the hardships and challenges a waste picker faces to handle the menstrual waste. While interviewing around 30 of them we found out nonetheless that almost everyone experienced the same health issues. The risks faced by workers in the waste sector go beyond the expected risks of infection and communicable diseases. Cuts and wounds, animal bites, chemical burns and inhalation of toxic gases, falls and traffic accidents, musculoskeletal problems, sexual violence and mental trauma are all part of their daily burden.("2Occupational health of waste pickers in Pune: KKPKP and SWaCH members push for health rights", 2013) Waste pickers often have no idea just how dangerous the materials they are sorting through may be. When repeated on a regular basis, the exposure to even small amounts of toxic materials, combined with poor general health, can have disastrous cumulative 
results.("2Occupational health of waste pickers in Pune: KKPKP and SWaCH members push for health rights", 2013) Soiled diapers and menstrual pads and cloths are considered to the most nauseating items which they have to handle. Everyday exposure to such filthy garbage and picking and segregating them manually, leads the waste pickers to experience headache, make their stomach churn, put you off their food and when they don't feed their tired body at the end of the day, they get weak and can't work the next day. Apart from these issues, redness into the eye, respiratory or breathing problems, skin irritation and vulnerability to gastrointestinal and musculoskeletal ailments are some of the very common problems experienced while handling waste, especially diapers and sanitary pads.

Conventional disposable menstrual products are bleached white, and this process creates the chemical dioxin, which is linked to immune system suppression, reproductive issues and cancer. Tampons can leave microscopic fibres in vaginal tissue, causing tiny cuts and creating a breeding ground for the bacteria that causes Toxic Shock Syndrome (TSS), which can be fatal. The absorbency of tampons also causes less serious but very unpleasant problems, upsetting the natural $\mathrm{pH}$ balance of the vagina and drying it out, which leads to discomfort, itching, rashes and infections.("Seeing RED: Sanitary Protection and The Environment")

\section{Magnitude of the Sanitary Waste Problem}

As the usage of sanitary napkins is increasing, the amount of sanitary waste generated every day is also increasing. It is equally important to address the issue of efficient disposal of this infectious waste. Currently as we see, a major part of this waste is dumped into landfills leading to tremendous land pollution. Sanitary napkins are flushed down the toilet under the name of convenience. All the drains ultimately meet the rivers in the city and thus water pollution increases. As seen in the above case-study, health of the waste pickers is affected to a great extent. These problems will increase in magnitude in the years to come if not taken care of at this crucial stage.

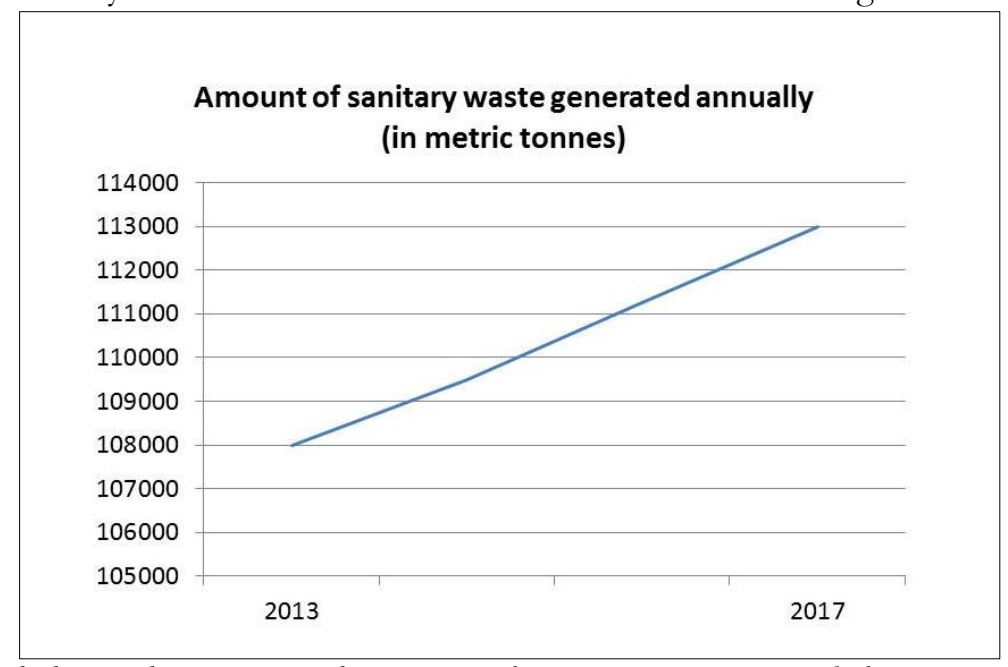

Fig. 8 A graph showing the increment in the generation of sanitary waste over a period of 4 years. 


\section{Our Solution}

Considering the above challenges and the magnitude of problems caused due to the lack of ability to handle infectious sanitary waste, a solution that was practical, viable, economical and convenient was required. Despite different measures and initiatives taken for proper disposal of sanitary waste, health issues of waste pickers and environmental degradation still persist. Thus, any solution proposed for this daunting issue needs to be effective as well as practical considering the culture and mentality of the society.

Today, PMC (Pune Municipal Corporation) spends 5 INR to dispose one sanitary pad. With a population of more than 1 million women in just one Pune city, the cost of collecting, manually segregating, transporting and burning menstrual waste is too huge to be reasonable. With our research and study into this problem, we have designed a compact sanitary napkin incinerator which you can install at your washroom or balcony and dispose off your waste at the generation point. No individual (irrespective of their economic condition) should handle someone else's harmful waste.

The sanitary napkin incinerator, which goes by the name "Dahini" (which means the one who burns), costs around 4000 INR which is 10 times cheaper than the average gigantic incinerators available in the Indian market. If this machine gets installed at every public washroom, women hostels, schools, colleges, households and other institutions, then it would create a big relief to manage menstrual waste and maintain the basic human health of overall community and other living beings. To create such a huge impact a lot of awareness programmes and campaigns need to be conducted to make women as well men aware of the best practices to manage the sanitary waste.
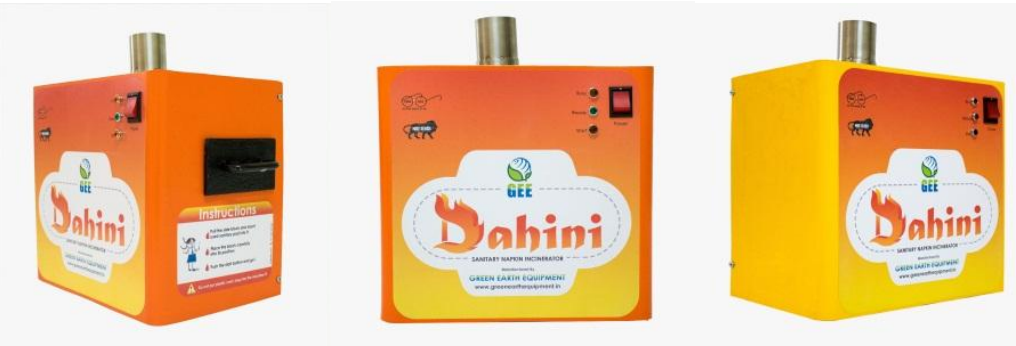

Fig. 9 Dabini, the sanitary waste incinerator

\subsection{Product Specifications}

Table 1. Product specifications

\begin{tabular}{|c|l|l|}
\hline Sr. No. & Specification & Value \\
\hline $\mathbf{1 .}$ & Product Dimensions $\left(\mathrm{L}^{*} \mathrm{H}^{*} \mathrm{D}\right)$ & $325 * 275 * 200 \mathrm{~mm}$ \\
\hline $\mathbf{2 .}$ & Electric consumption per napkin & $150 \mathrm{Watt}$ \\
\hline $\mathbf{3 .}$ & Connected load & $500 \mathrm{Watt}$ \\
\hline $\mathbf{4 .}$ & Capacity & 1 to 5 napkins \\
\hline $\mathbf{5 .}$ & Incineration cycle duration & 15 minutes \\
\hline
\end{tabular}


The impact the solution would have:

- Health of waste pickers - A large impact of this project would be on the lives of waste pickers and towards extricating them from the violations of basic human integrity.

- Lesser waste into landfills - Since the incinerator discourages from putting any sanitary waste into the dustbins or landfills, there would be eventually reduced number of landfill requirements.

- Reduced water pollution - A huge chunk of menstrual waste is openly thrown into the rivers and other water bodies in India. With the introduction and acceptance of such convenient incinerators, we could save our water bodies from a huge chunk of pollutants.

- Lesser probability of infections - Since the filthy waste would no longer be in contact with any other human being or exposed for a prolonged duration, the changes of infections due to them goes away.

- Dignity of a woman remains intact - No need for a woman to feel embarrassed for her menstrual napkin being exposed and handled by another human being. She can now take charge of the situation by managing her own waste.

- Reduced costs for disposal - The humongous cost attached to incinerator sanitary waste gets reduced up to 10 times which in turn encourages more usage.

- Improved health and sanitation - When not even a single menstrual napkin comes out of a building or house or institution, we would ensure increased overall sanitary health and awareness.

The solution mentioned above promises to overcome almost every challenge of handling and disposing sanitary waste, however the only factor considered by public is the smoke it generates. Whereas we do not deny that this incinerator contributes to some amount of smoke or pollution, the intensity of its pollution is almost negligible as compared to the air pollution created by our everyday activities like cigarette smoking or driving. The amount of Carbon Monoxide (CO) generated by smoking 3 cigarettes in 30 minutes is $0.5 \%(\mathrm{v} / \mathrm{v})$, whereas, the CO generated by burning 3 pads in 30 minutes is $0.2 \%(\mathrm{v} / \mathrm{v})$. While cigarette smoking is openly accepted in the society, we urge to consider even this machine, which is capable of eradicating major sanitation problems as opposed to simply creating pollution.

\section{Conclusion}

Menstrual waste and its impact on the environment and society have always been given lesser eminence as compared to the rest of the Municipal Solid Wastes. A woman's hygiene and sanitation should always be given higher priority, as also to the basic human dignity of the millions of waste pickers who handle and segregate someone else's waste. Thus a solution to this ever growing problem was required to be practical, convenient and economical. Our solution mentioned, is capable of overcoming almost every difficulty and thus promises healthier and cleaner sanitation and surrounding environment. Problems faced by waste-pickers can be handled efficiently if this solution is put to use extensively. It is also crucial that the importance of proper sanitation and 
hygiene be taught to young children in their growing age so that this problem will cease to persist in the coming future.

\section{Acknowledgement}

This research was supported by Mr. Ravindra H Gadre, Co-Founder of Green Earth Equipment and the innovator of Dahini. We are thankful to him for providing us with timely guidance and his expertise into the field of engineering and research.

\section{References}

Kaur R. et al, (2018). Menstrual Hygiene, Management, and Waste Disposal: Practices and Challenges Faced by Girls/Women of Developing Countries. Hindawi Journal of Environmental and Public Health. 2018, 1-9. Doi: 10.1155/2018/1730964

Sharholy M. et al, (2007). Municipal solid waste management in Indian cities - A review. Waste Management 28 (2008), 459-467. Doi: 10.1016/wasman.2007.02.008

${ }^{1}$ Management of Menstrual Waste. Retrieved from http://www.path.org/publications/files/ ID_mhm_mens_waste_man.pdf/

2Occupational health of waste pickers in Pune: KKPKP and SWaCH members push for health rights. (2013). Retrieved from http://www.mfcindia.org/main/bgpapers/bgpapers2013/am/bgpap2013Vv.pdf

${ }^{3}$ Waste pickers. Retrieved from http://www.wiego.org/informal-economy/occupational-groups/wastepickers

Sahoo, P. (2016, May 28). A growing concern: Disposing off used sanitary napkins. Retrieved from https://www.hindustantimes.com/health-and-fitness/a-growing-concern-disposing-off-usedsanitary-napkins/story-jq7S96rYBN3BOCk5gTUwPM.html

Sripada, K. (2014, June 01). Why menstruation is a nightmare for many women in India. Retrieved from http://www.firstpost.com/living/why-menstruation-is-a-nightmare-for-many-women-in-india1550781.html

How Disposable Sanitary Napkins Affect Environment. (2017, June 5). Retrieved from https://everylifecounts.ndtv.com/disposable-sanitary-napkins-affect-environment-13914

Shreya, (2016, November 4). The Ecological Impact of Feminine Hygiene Products. Retrieved from https://rctom.hbs.org/submission/the-ecological-impact-of-feminine-hygiene-products/

Syren, F. (2016, October 10). The Environmental Impact of Menstrual Pads and Tampons. Retrieved from https://green-mom.com/environmental-impact-menstrual-pads-tampons/\#.Wr3ntWpubIU

Seeing RED: Sanitary Protection and The Environment. Retrieved from https://www.wen.org.uk/environmenstrual/ 